\title{
Preparation of full-bio-based nanofiltration membranes
}

\author{
Muhammad Azam Rasool, Ivo F.J. Vankelecom \\ Membrane Technology Group, Division CMACS, Faculty of Bioscience Engineering, KU Leuven, Celestijnenlaan 200F, PO Box 2454, 3001, Leuven, Belgium
}

\section{A R T I C L E I N F O}

\section{Keywords:}

Glycerol derivatives

Cellulose acetate

Bio-based solvents

Polymeric membranes

Nanofiltration

\begin{abstract}
A B S T R A C T
Cellulose acetate (CA) as polymer, glycerol derivatives (namely triacetin, diacetin, monoacetin or glycerolformal) as solvents and 2-methyltetrahydrofuran (2-MeTHF) as co-solvent were selected as bio-based ingredients for the preparation of full-bio-based nanofiltration membranes via non-solvent induced phase separation (NIPS). Membrane performance was investigated using an aqueous rose bengal (1017Da) solution (RB/ $\mathrm{H}_{2} \mathrm{O}$ ) as feed. Membrane morphologies were characterized using SEM (scanning electron microscopy). Both kinetic and thermodynamic aspects of the phase inversion process were studied in detail to gain more insight in the membrane formation process. When implementing a 90s evaporation step prior to coagulation, rejection increased with increasing 2-MeTHF concentration in the casting solution in the case of diacetin and triacetin solvents. In the case of monoacetin and glycerol-formal based casting solutions, evaporation had a less significant impact on RB rejection even though the same volatile co-solvent was used. The best membranes were finally obtained using diacetin as a solvent and 2-MeTHF as co-solvent with permeances ranging from 5.5 to $12.8 \mathrm{~L} / \mathrm{m}^{2} \mathrm{~h}$ bar for membranes with $>90 \% \mathrm{RB}$ rejections.
\end{abstract}

\section{Introduction}

Due to low energy consumption and no creation of waste streams, membrane technology offers an excellent alternative to traditional separation technologies for separation and purification of industrial products and wastewater [1]. Nanofiltration (NF) is a pressure driven process, used for the separation of organic molecules or divalent salts in the range of 200-1000Da from (aqueous or organic) feed solutions [2-7]. NF has a lot of applications in waste water treatment $[8,9]$ and a large potential in chemical, pharmaceutical and food industry [7, 10-14].

Most preparation methods in membrane technology are based on the use of toxic solvents $[15,16]$. Design of safer processes, by e.g. applying harmless solvents, has gained importance due to growing concerns regarding health and environmental impacts $[2,17,18]$. Approaches to prepare polymeric membranes in a more environmentally-friendly way are based on implementation of green chemistry principles, as described by UNEPA in the 1990s $[19,20]$. The aim of green chemistry is to overcome health, safety and environmental problems at the sources by designing safer and cleaner chemical reactions and processes for chemical industry $[17,21]$.

Asymmetric CA-membranes are very well known for water treatment, desalination of water, $\mathrm{CO}_{2}$ separation and pervaporation [22,23].
These asymmetric CA-membranes are prepared via the so-called phase inversion technique in which a homogenous polymer solution is cast in the form of a thin film, mostly followed by a coagulation step, to form a membrane. In this process, non-solvent diffuses into the cast film, while solvent diffuses out. The morphology of the nascent membrane depends on the exchange rate and the type of solvent and non-solvent and on the polymer type [12,24-28]. CA is a renewable and biodegradable, bio-based polymer obtained via acetylation of hydroxyl moieties of cellulose [29] and is a relatively cheap material [30].

Traditional solvents currently applied in polymer membrane preparation are dimethyl sulphoxide (DMSO), acetone, $N$-methyl-2-pyrrolidone (NMP), 1,4-dioxane, $N, N$-dimethylformamide (DMF), dichloromethane or chloroform [12,31-33]. All have excellent characteristics for membrane formation but most are toxic and harmful to human health and the environment. Additionally, these solvents are obtained from petroleum-based resources [20,34,35]. Soroko et al. [2] proposed to replace 1,4-dioxane and DMF by less toxic DMSO and acetone respectively. Green solvents, like $\gamma$-butyrolactone [36], $\gamma$-valerolactone [37], methyl lactate [38] or ethyl lactate [39,40], triethyl phosphate [41], DMSO [2] and ionic liquids [42,43], have also been suggested to replace solvents in membrane preparation.

Asymmetric membrane prepared via non-solvent induced phase inversion NIPS mainly typically consist of top a thin selective layer on a

\footnotetext{
* Corresponding author.

E-mail address: ivo.vankelecom@kuleuven.be (I.F.J. Vankelecom).
} 
Table 1

Chemical structure and physical properties of solvents and polymer used in this work.

\begin{tabular}{|c|c|c|c|c|}
\hline Chemical name & Chemical structure & MW (Da) & Purity (wt $\%)$ & Viscosity (mPa.s) \\
\hline Triacetin & 11 & 218.2 & $>99$ & 19 \\
\hline Diacetin $^{\mathrm{a}}$ & & 176.2 & $>40$ & 48 \\
\hline Monoacetin $^{\mathrm{b}}$ & & 134.1 & $>40$ & 112 \\
\hline Glycerol-formal $^{\mathrm{C}}$ & & 104.1 & $>98$ & 13 \\
\hline & 4-hydroxymethyl & & & \\
\hline 2-MeTHF & & 86.0 & 99 & 0.55 \\
\hline $\mathrm{CA}$ & 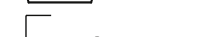 & $\sim 30,000$ & 97 & \\
\hline
\end{tabular}

*Prices of the solvents are taken from the Sigma-Aldrich and TCI chemicals Belgium websites.

a Diacetin also contains glycerol, triacetin and monoacetin.

b Monoacetin also contains glycerol, triacetin and diacetin.

c Glycerol-formal is a mixture of 5-hydroxy-1,3-dioxane and 4-hydroxymethyl-1,3-dioxolane.

porous sublayer. The membrane performance mainly depends on the top layer, which determines the selectivity of the membrane and the porous sublayer provides strength and mechanical stability. The membrane performance is linked to its structure, developed during the phase inversion process, which depends on numerous factors including polymer type and concentration, solvent type, additives or the use of cosolvents. Other parameters are solvent and non-solvent diffusion rates and miscibility, temperature, annealing and evaporation time [24-26, 44-51].

Glycerol is obtained as a byproduct in oleochemistry, produced by triglyceride transesterification with alcohols [38]. The annual production of glycerol (1.3 million metric tons) is much more higher than the total demand [38]. So, it is essential to find alternative uses for glycerol as a solvent, or to convert glycerol into derivatives [52-57].

The objective of this work is to find a possible sustainable solution to replace current toxic materials with environmentally friendly materials in membrane preparation. CA is chosen as a bio-based polymer and glycerol derivatives as sustainable, green solvents for membrane fabrication. Glycerol derivatives are risk-free related to health and safety. In addition, the green alternative 2-MeTHF was used as volatile co-solvent
[58]. 2-MeTHF is derived from renewable biomass via hydrogenation of furfural and costs around 75-90 EUR/L for lab-scale purchases (TCI Fine Chemical, Belgium). As a standard non-woven support material was applied at this stage, this material is the only non-bio-based one in this work.

\section{Experimental}

\subsection{Materials}

Cellulose acetate (39.9 wt\% acetyl groups) was purchased from Sigma Aldrich (Belgium) and solvents were purchased from TCI Fine Chemicals (Belgium) and used as received (Table 1). CA was dried at $100{ }^{\circ} \mathrm{C}$ for 1 day prior to use. Non-Woven polypropylene is an ecofriendly thermoplastic polymer that is melted down and recycled, used as a support for membrane preparation.

\subsection{Membrane preparation}

CA-based membranes were prepared by changing the CA 
Table 2

Concentration of CA and co-solvents, applied evaporation time, as well as solvent and non-solvent selection per membrane used in membrane preparation.

\begin{tabular}{|c|c|c|c|c|c|}
\hline Membrane ID & CA-concentration (wt $\%$ ) & Solvent & ${ }^{\mathrm{a}}$ Co-solvent (wt $\%$ ) & Evaporation time (s) & Non-solvent \\
\hline T9 & 9 & Triacetin & - & - & Ethanol \\
\hline $\mathrm{T} 11$ & 11 & Triacetin & - & - & Ethanol \\
\hline $\mathrm{T} 13$ & 13 & Triacetin & & & Ethanol \\
\hline T13CS16 & 13 & Triacetin & 2-MeTHF (16) & & Ethanol \\
\hline T13CS33 & 13 & Triacetin & 2-MeTHF (33) & & Ethanol \\
\hline T13CS50 & 13 & Triacetin & 2-MeTHF (50) & & Ethanol \\
\hline T13CS16E & 13 & Triacetin & 2-MeTHF (16) & 90 & Ethanol \\
\hline T13CS33E & 13 & Triacetin & 2-MeTHF (33) & 90 & Ethanol \\
\hline T13CS50E & 13 & Triacetin & 2-MeTHF (50) & 90 & Ethanol \\
\hline D10 & 10 & Diacetin & - & - & Water \\
\hline D12.5 & 12.5 & Diacetin & - & - & Water \\
\hline D15 & 15 & Diacetin & - & - & Water \\
\hline D16CS16 & 16 & Diacetin & 2-MeTHF (16) & & Water \\
\hline D16CS33 & 16 & Diacetin & 2-MeTHF (33) & & Water \\
\hline D16CS50 & 16 & Diacetin & 2-MeTHF (50) & & Water \\
\hline D16CS16E & 16 & Diacetin & 2-MeTHF (16) & 90 & Water \\
\hline D16CS33E & 16 & Diacetin & 2-MeTHF (33) & 90 & Water \\
\hline D16CS50E & 16 & Diacetin & 2-MeTHF (50) & 90 & Water \\
\hline M8 & 8 & Monoacetin & - & - & Water \\
\hline M10 & 10 & Monoacetin & - & - & Water \\
\hline M14CS16 & 14 & Monoacetin & 2-MeTHF (16) & - & Water \\
\hline M14CS33 & 14 & Monoacetin & 2-MeTHF (16) & 90 & Water \\
\hline M14CS50 & 14 & Monoacetin & 2-MeTHF (33) & - & Water \\
\hline M14CS16E & 14 & Monoacetin & 2-MeTHF (33) & 90 & Water \\
\hline M14CS33E & 14 & Monoacetin & 2-MeTHF (50) & & Water \\
\hline M14CS50E & 14 & Monoacetin & 2-MeTHF (50) & 90 & Water \\
\hline G10 & 10 & Glycerol-formal & - & - & Water \\
\hline G15 & 15 & Glycerol-formal & - & - & Water \\
\hline G20 & 20 & Glycerol-formal & & - & Water \\
\hline G20CS16 & 20 & Glycerol-formal & 2-MeTHF (16) & - & Water \\
\hline G20CS33 & 20 & Glycerol-formal & 2-MeTHF (33) & - & Water \\
\hline G20CS50 & 20 & Glycerol-formal & 2-MeTHF (50) & - & Water \\
\hline G20CS16E & 20 & Glycerol-formal & 2-MeTHF (16) & 90 & Water \\
\hline G20CS33E & 20 & Glycerol-formal & 2-MeTHF (33) & 90 & Water \\
\hline G20CS50E & 20 & Glycerol-formal & 2-MeTHF (50) & 90 & Water \\
\hline
\end{tabular}

${ }^{a}$ wt.\% of 2-MeTHF is calculated as wt. 2-MeTHF/(wt. 2-MeTHF + solvent).

concentration (8-20 wt\%) in glycerol derivatives depending on the solubility limit as well as by changing the 2-MeTHF concentration as cosolvent (10-50 wt\%) and with or without 90 s evaporation time prior to coagulation via immersion precipitation in the non-solvent. Details of CA-concentration, solvent and co-solvent used for each membrane are presented in Table 2 . All polymer solutions were prepared at $22{ }^{\circ} \mathrm{C}$ and stirred magnetically overnight prior to membrane casting.

Polymer solutions were cast at a wet thickness of $200 \mu \mathrm{m}$ at $0.5 \mathrm{~m} /$ min on a non-woven fabric support. It is noted that all other membrane samples were given around $5 \mathrm{~s}$ to transfer the cast film from the casting apparatus. In all cases, water was used as non-solvent, except for triacetin-based membranes where ethanol was applied. All membranes were kept in water prior to nanofiltration.

For each category of casting solvent, different concentrations of cosolvents $(16,33$ and $50 \mathrm{wt} \%)$ were added in the casting solution for membrane preparation with or without a 90 s evaporation step prior to coagulation in the respective non-solvent (Table 2).

\subsection{Cloudpoint determination}

To plot the phase diagram, cloudpoints of each polymer system were determined by visual observation of a turbidity change of the CA solutions, while titrating them with non-solvent [38]. All polymer solutions were weighed prior to titration experiments. Appearance of turbidity in the CA solution confirmed that cloudpoints were reached if the turbidity did not disappear even after continuous stirring for more than $1 \mathrm{~h}$ at $30{ }^{\circ} \mathrm{C}$. The resulting mixture (polymer + solvent system + non-solvent) was weighed again to determine the amount of added non-solvent and the concentration (to be plotted in the phase diagrams) was calculated using this final composition [24,25].

\subsection{Viscosity measurements}

An Anton Paar MCR501 rheometer was used for the rheological measurements on a stress-controlled mode with cone-plate geometries. The procedure was adapted from literature [24,25,38]. For the low-viscous samples (viscosities up to $10 \mathrm{~Pa}$ s), a cone-plate geometry of $50 \mathrm{~mm}$ with cone angle of $1^{\circ}$ was used, whereas a cone-plate geometry of $25 \mathrm{~mm}$ and $2^{\circ}$ cone angle was used for the high-viscous samples. The sample temperature was controlled at $23.0{ }^{\circ} \mathrm{C}$ with a Peltier element. Viscosity as function of shear rate was probed in steady shear flow [from 0.01 to 10 s- 1 with 5 data points per decade] [24,25,38]. The RheoPlus software (Anton Paar GmbH, Austria) was used for data acquisition and analysis. A Newtonian plateau was observed for all solutions and hence, the zero-shear viscosity was calculated as the average taken over the first five data points [shear rates between 0.01 and $0.11 / \mathrm{s}$ ].

\subsection{Membrane performance}

Filtrations experiments were done in a dead-end filtration cell with a high throughput filtration system (HTM) KU Leuven [27], at $20^{\circ} \mathrm{C}$ under pressures ranging from 2 to 20 bar. 8 membrane coupons were placed in the filtration setup and sealed with Viton ${ }^{\circledR}$ O-rings for simultaneous filtration, using a $0.000175 \mathrm{~m}^{2}$ active surface area for each coupon. The feed solution of $40 \mu \mathrm{M}$ Rose Bengal (RB, 1017Da, Sigma-Aldrich) was prepared in distilled water $\left(\mathrm{H}_{2} \mathrm{O}\right)[37,38,59]$.

$\mathrm{RB} / \mathrm{H}_{2} \mathrm{O}$ solutions were stirred at $300 \mathrm{rpm}$, using a magnetic stirrer to minimize concentration polarization. Permeance ( $\mathrm{L} / \mathrm{m}^{2}$.h.bar) is calculated using eq. (1) by weighing the collected permeate, while retention ( $\mathrm{R}$ in \%) is calculated by eq. (2). $C_{F}$ represents the concentration of the initial feed, while $C_{P}$ represents the concentration of the permeate. A PerkinElmer Lambda 12 UV-vis spectrophotometer was used to record 
Table 3

HSPs of CA and solvents.

\begin{tabular}{|c|c|c|c|c|c|c|}
\hline \multirow[t]{2}{*}{ Solvent/polymer } & \multicolumn{3}{|c|}{ Hansen solubility parameters } & \multirow[b]{2}{*}{$\delta \mathrm{MPa}^{1 / 2}$} & \multirow[b]{2}{*}{$\mathrm{R}_{\mathrm{o}} \mathrm{MPa}^{1 / 2}$} & \\
\hline & $\delta_{\mathrm{D}} \mathrm{MPa}^{1 / 2}$ & $\delta_{\mathrm{P}} \mathrm{MPa}^{1 / 2}$ & $\delta_{\mathrm{H}} \mathrm{MPa}^{1 / 2}$ & & & \\
\hline \multirow[t]{2}{*}{ CA } & 16.0 & 7.5 & 13.5 & 22.2 & 8.8 & \\
\hline & & & & & $\mathrm{Ra} \mathrm{MPa}^{1 / 2}$ & $\mathrm{RED}=\mathrm{Ra} / \mathrm{R}_{\mathrm{o}}$ \\
\hline Triacetin & 16.5 & 4.5 & 9.1 & 19.4 & 5.4 & 0.6 \\
\hline Diacetin & 16.4 & 8.9 & 14.2 & 23.4 & 1.8 & 0.2 \\
\hline Monoacetin & 14.9 & 17.5 & 18.9 & 29.8 & 11.6 & 1.1 \\
\hline Glycerol-formal & 16.4 & 17.3 & 16.9 & 29.3 & 10.5 & 1.2 \\
\hline 2-Methyltetrahydrofuran & 16.9 & 5.0 & 4.3 & 18.1 & 9.7 & 1.1 \\
\hline
\end{tabular}
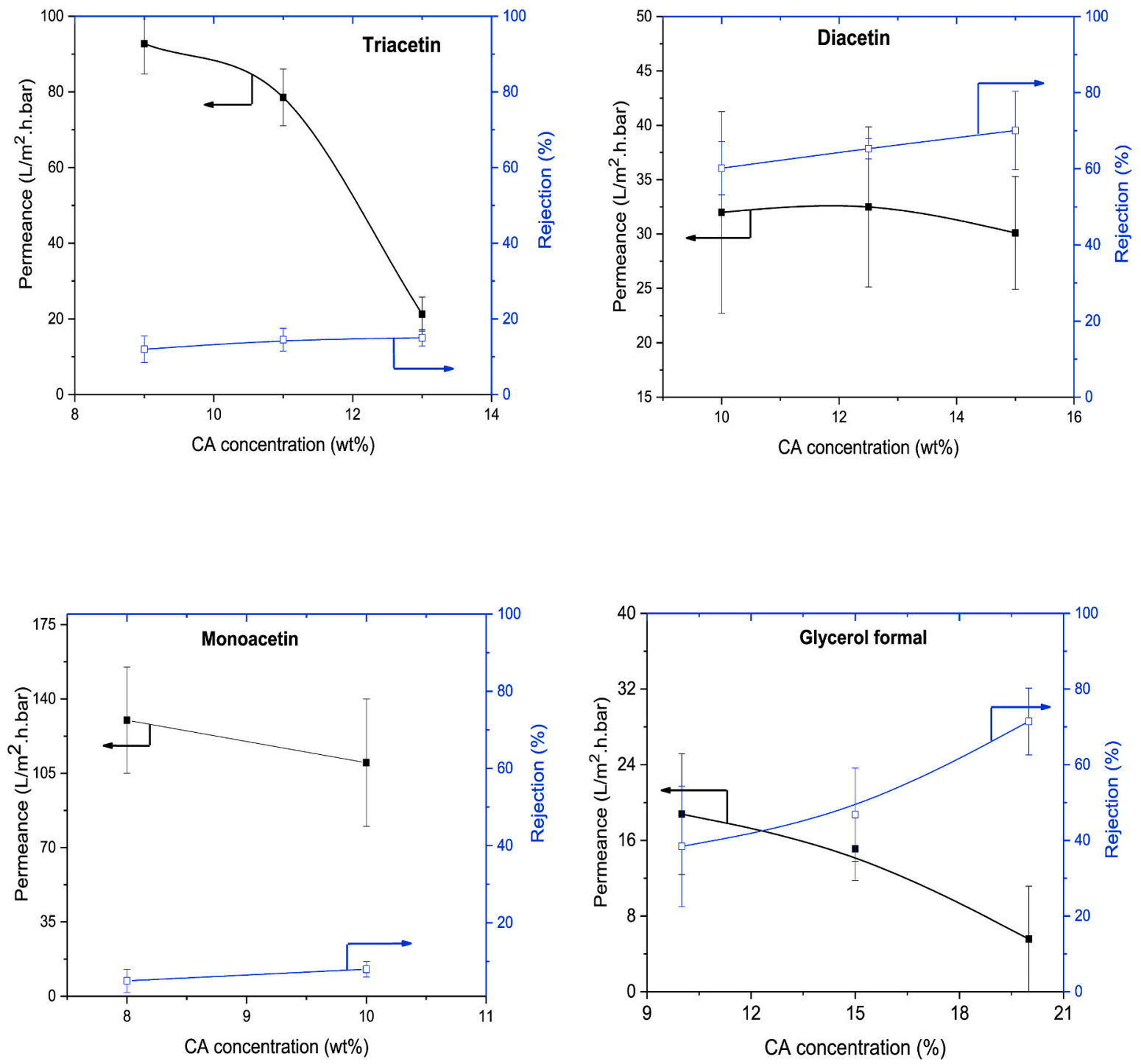

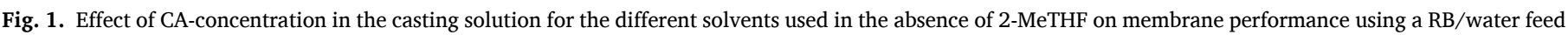
at $2-10$ bar.

the $\mathrm{RB} / \mathrm{H}_{2} \mathrm{O}$ concentration in the permeate at $549 \mathrm{~nm}$.

Permeance $\left(L_{p}\right)=\frac{\operatorname{vol}[L]}{\text { membrane area }\left[m^{2}\right] . \Delta p[\text { bar }] \text {. time }[h]}$

$\operatorname{Retention}(R)=\left(1-\frac{C_{P}}{C_{F}}\right) \times 100[\%]$

\subsection{Hansen solubility parameters}

Solubility parameters are helpful to verify the solubility of a polymer in a solvent system. For Hansen solubility parameters (HSP) calculation, the heat of vaporization energy is divided into three different parameters and processed as 3-dimensional vectors corresponding to dispersive forces $\left(\delta_{\mathrm{D}}\right)$ polar forces $\left(\delta_{\mathrm{P}}\right)$ and hydrogen bonding $\left(\delta_{\mathrm{H}}\right)$. The Hildebrand parameter $\left(\delta_{\mathrm{t}}\right)$, is a geometric means of HSP parameters as calculated by 

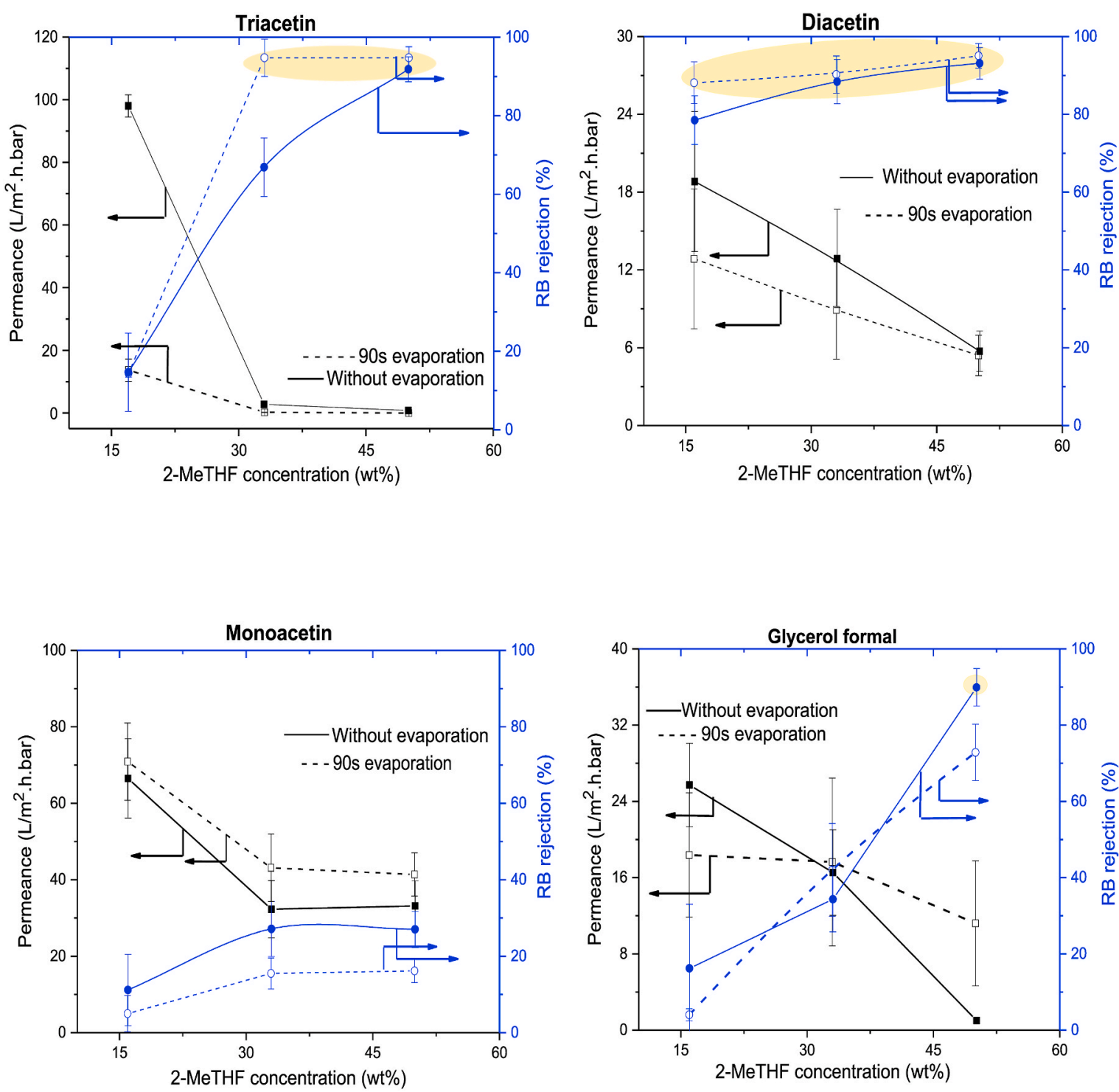

Fig. 2. Effect of 2-MeTHF (co-solvent) concentration in the casting solution on membrane performance represented by full lines, while the effect of evaporation step (90s) prior to immersion in non-solvent of these casting films on membrane performance is represented by dotted line. Membranes with NF properties are marked with the light-yellow shaded zones. (For interpretation of the references to colour in this figure legend, the reader is referred to the Web version of this article.)

equation (3) [60]. The total solubility values of CA and glycerol derivatives are not very different in values and in theory, they could thus form homogeneous solutions (Table 3 ).

$\delta_{t}=\sqrt{\delta_{D}^{2}+\delta_{P}^{2}+\delta_{H}^{2}}$

The interaction distance $(R a)$ between two solubility parameters is calculated using equation (4). A small value of $R a$ indicates that the solvent/polymer system is able to form a homogeneous solution.

$R_{a}=\left[\sqrt{4\left(\delta_{D 2}-\delta_{D 1}\right)^{2}+\left(\delta_{P 2}-\delta_{P 1}\right)^{2}+\left(\delta_{H 2}-\delta_{H 1}\right)^{2}}\right]$

The relative energy difference $(R E D)$ is another parameter used to describe the ability of a solvent to dissolve a polymer to form a homogeneous solution, which is equal to $\mathrm{Ra} / \mathrm{R}_{\mathrm{o}}$. A RED value under 1 represents that the solvent polymer system is compatible to form homogeneous solution. HSP values of solvent blends were calculated as described by Hansen et al. [60] For RED values, see Table 3, while HSP values for solvents and co-solvent were taken from literature [40,60,61]. $\mathrm{R}_{0}$ is the interaction radius of the polymer [38].

\subsection{Membrane morphology}

A JEOL JSM 6010LV scanning electron microscope (SEM) was used to evaluate the membrane morphology. Membrane samples were broken in liquid nitrogen to acquire cross-sections. For charge reduction under electron beam, a Au/Pd layer (around $2 \mathrm{~nm}$ ) thick was deposited on the samples by means of a Cressington HR208 sputter coater.

\section{Results and discussion}

\subsection{Parameters influencing membrane performance}

\subsubsection{CA-concentration}

Although the RED-value for monoacetin is higher than 1.0, still it solubilized CA, possibly due to the fact that monoacetin also contains diacetin and triacetin. High polymer concentrations in casting solutions generally lead to denser membranes [5,24,34,62]. Indeed, the permeances reduced drastically at higher polymer concentration for triacetin and glycerol-formal, while much less for diacetin and monoacetin, as shown in Fig. 1. In line with this, rejections increased, 


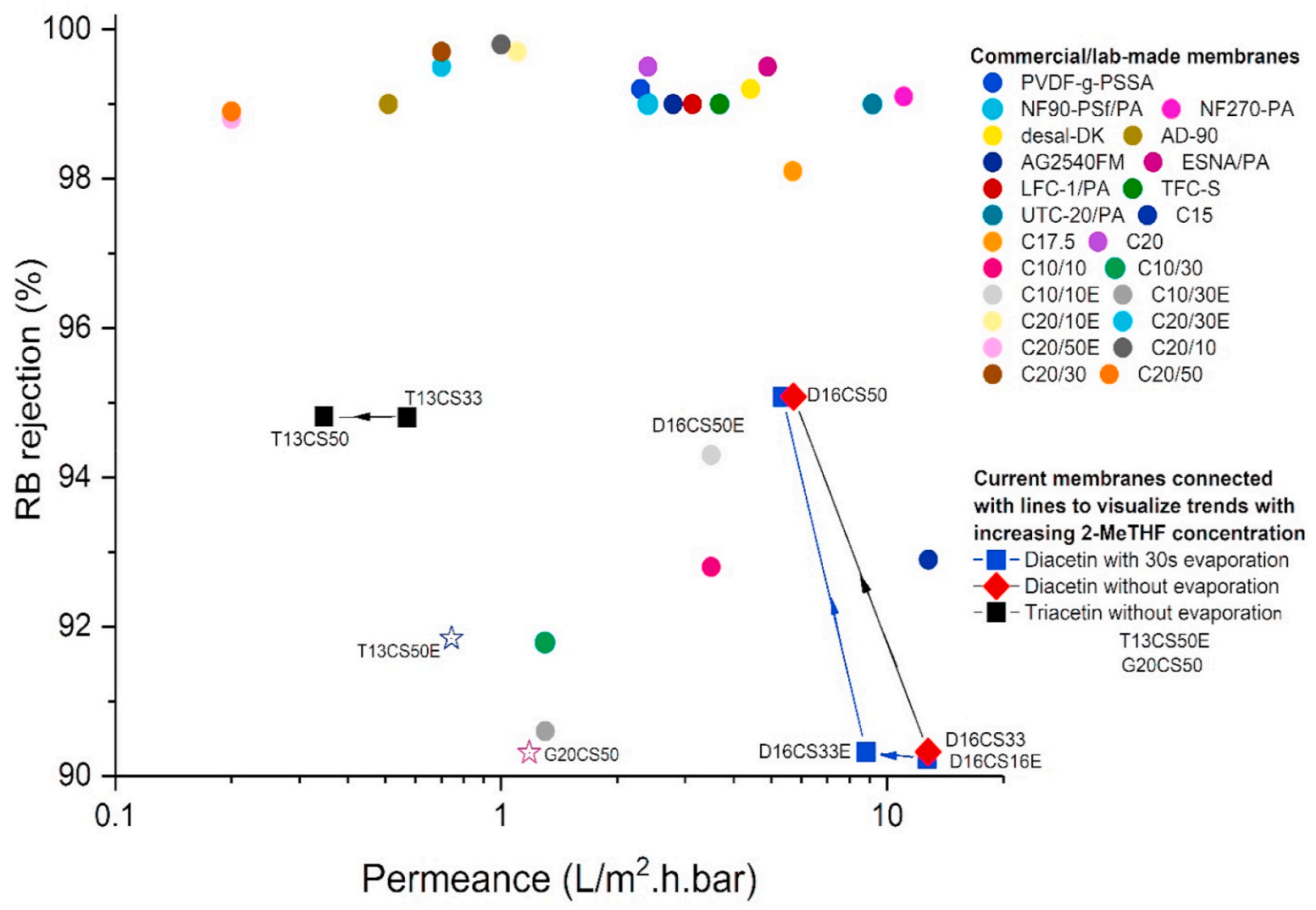

Fig. 3. Rejection vs permeance plot for membranes from current work with NF properties, compared with commercial and lab-made membranes, all using $\mathrm{RB} / \mathrm{H}_{2} \mathrm{O}$ as feed solution (supporting information, table 5).

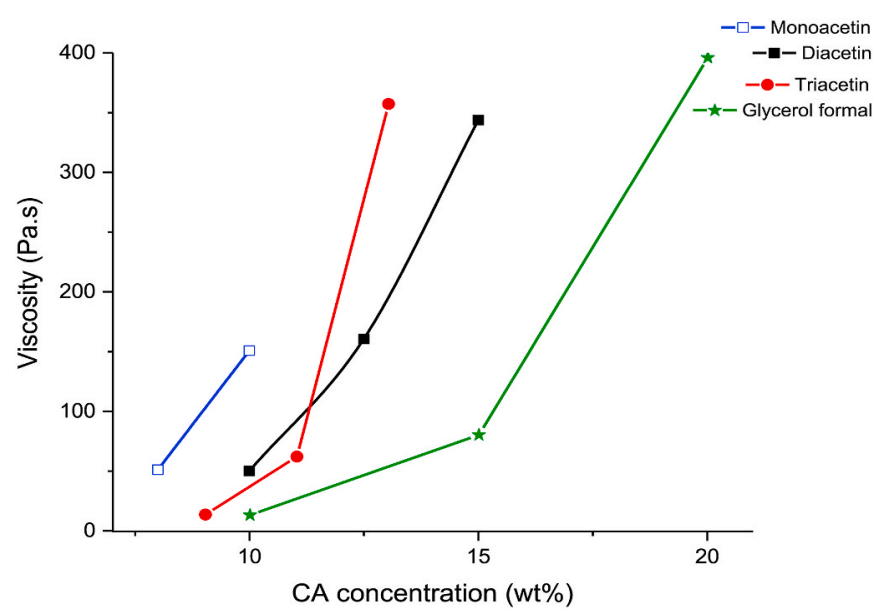

Fig. 4. Effect of the CA-concentration on the viscosity of the casting solutions for the 4 solvent systems.

even though only slightly. In some cases, quite large experimental errors accumulated on these data, but still the trends seen reasonable. The $\mathrm{x}$-axes in Fig. 1 all stop at different values, illustrating the different CA solubility power of each solvent.

The solubility limit of CA in triacetin was around $13 \mathrm{wt} \%$. It was possible to dissolve more CA upon heating, but casting the film was problematic due to the high viscosity of the cooled down CA solution.

It was not possible to reach CA-concentration over $10 \mathrm{wt} \%$ in monoacetin at room temperature due to the high viscosity of this solvent (Table 2). Due to these intrinsically low CA-concentrations in the casting solution, the performance of the resulting membranes did not reach the
$\mathrm{NF}$ criterium of $>90 \% \mathrm{RB}$ rejection.

The low viscosity of glycerol-formal allowed to cast CA-membrane from solution with more than $20 \%$ at room temperature. None of these membranes however fulfilled the NF criterium of $>90 \% \mathrm{RB}$ rejection.

\subsubsection{Co-solvent}

Due to the addition of co-solvent (2-MeTHF) in the casting solution, membrane morphology and performance are considerably influenced $[25,63]$. In this work, the low boiling $(80.2 \mathrm{C})$, non-viscous, bio-based, green solvent, 2-MeTHF was used as co-solvent to improve membrane performance, especially to increase rejections to the NF-level [64]. Co-solvent concentrations ranging from 16 to $50 \mathrm{wt} \%$ were used in the casting solutions to prepare CA membranes using the four different glycerol derivatives (Table 2). Due to the lower viscosity of 2-MeTHF as compared to these glycerol derivatives, it was possible to dissolve more CA in the presence of co-solvent. Based on the Hildebrand-parameters, 2-MeTHF is also a better solvent for CA than monoacetin and glycerol formal (Table 3).

Using triacetin as main solvent, a $13 \mathrm{wt} \% \mathrm{CA}$ concentration was used in the casting solution to study the addition of 2-MeTHF as co-solvent. Permeance decreased with increasing 2-MeTHF concentration in the casting solution, while RB rejection increased. This could be expected from the addition of a volatile solvent [63], even though evaporation time before coagulation was kept minimal. In practice, this evaporation time turned out to be a few seconds because of mere practical reasons of handling the cast film.

In the case of diacetin, a $16 \mathrm{wt} \% \mathrm{CA}$-concentration was selected to prepare membranes with co-solvent. Addition of 2-MeTHF to the casting solution significantly improved the RB rejection till over $90 \%$ with still good permeances.

For the monoacetin system, addition of 2-MeTHF allowed to increase 


\section{Triacetin}

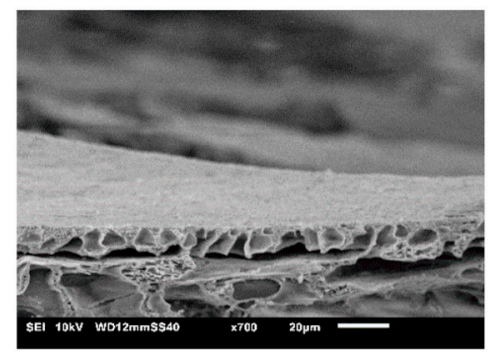

T9

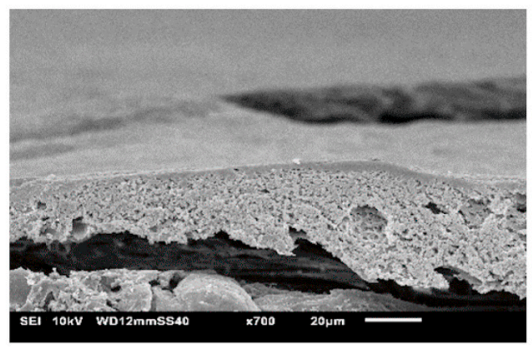

T11

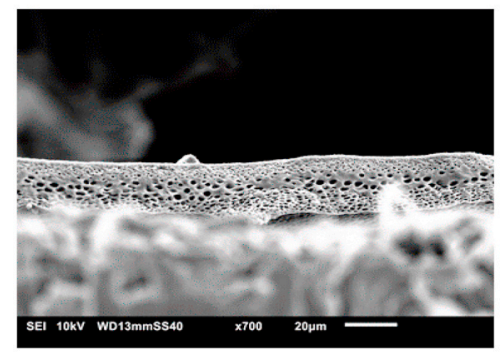

$\mathrm{T} 13$

\section{Diacetin}

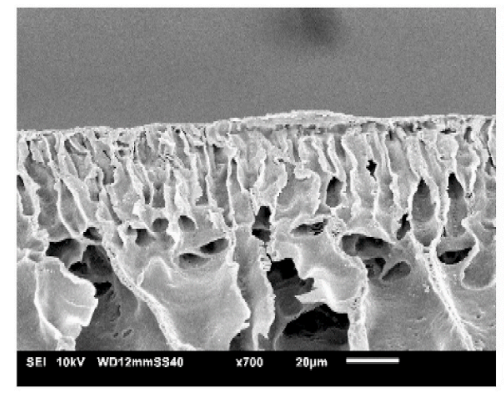

D10

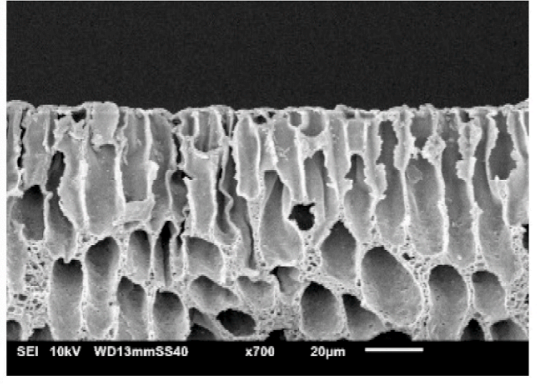

D12.5

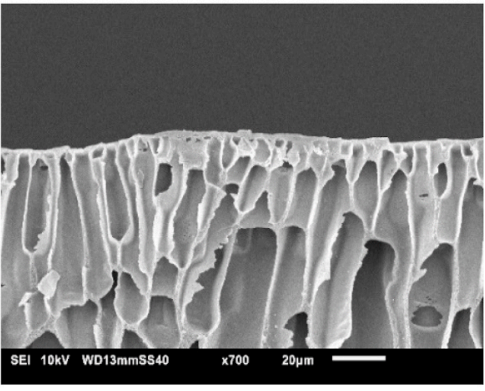

D15

\section{Monoacetin}

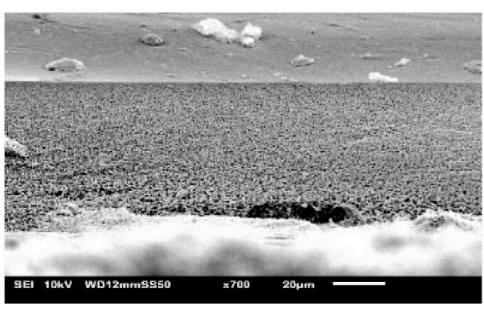

M8

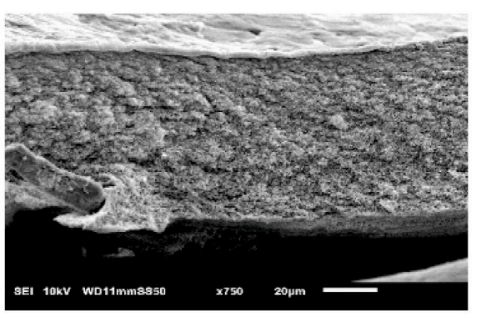

M10

\section{Glycerol-formal}

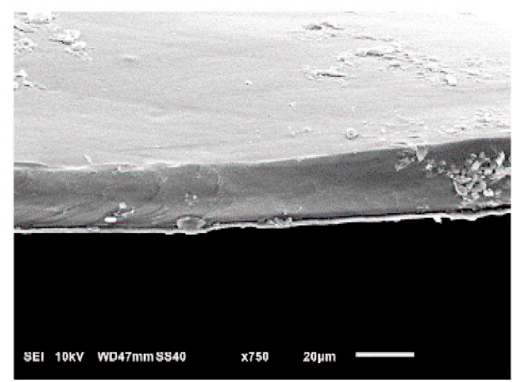

G10

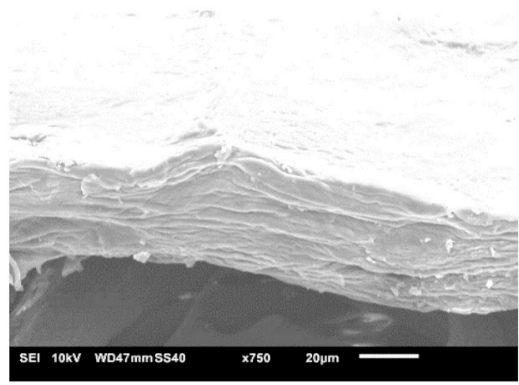

G15

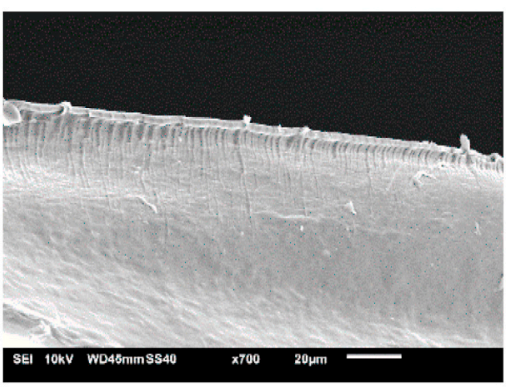

G20

Fig. 5. SEM images of cross-sections of CA membranes cast from different polymer concentration solutions using glycerol derivatives.

the CA-concentration in the casting solution up to $14 \mathrm{wt} \%$. RB rejections remained below $30 \%$ for all membranes prepared using 2-MeTHF.

As glycerol-formal exists as a mixture of two isomers, it is less viscous than other glycerol derivatives. A $20 \mathrm{wt} \%$ CA-concentration could thus be combined with different concentrations of 2-MeTHF. At $50 \mathrm{wt} \% 2$ MeTHF concentration, NF membranes could be obtained with a RB rejection higher than $90 \%$ and permeance around $1.0 \mathrm{~L} / \mathrm{m}^{2} \mathrm{~h}$ bar $[32,65$,
$66]$.

Under these conditions of adding co-solvent but not including an explicit evaporation step, only membranes T13CS50, D10CS33, D10CS50 and GF20CS50 thus managed to reach NF-qualifying rejections with reasonably good fluxes especially for the diacetin-based membranes (Fig. 2). 


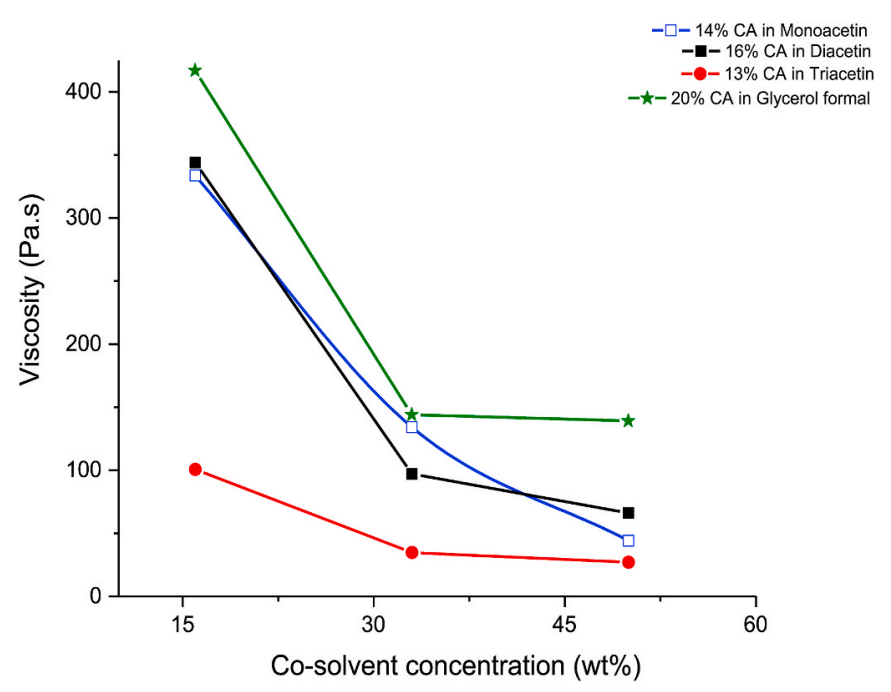

Fig. 6. Effect of the co-solvent (2-MeTHF) concentration in the casting solutions on the viscosity of CA-solutions prepared in the 4 solvents.

\subsubsection{Evaporation time before phase inversion}

When at least one volatile solvent is used in the casting solution, an extended evaporation step with longer time is applied to create a denser membrane surface [25]. Due to evaporation, a higher polymer concentration is locally produced at the top surface of the film. This denser layer is expected to act as a resistance barrier between the non-solvent bath and the deeper membrane region, which slows down the demixing process and produces membranes with densified structures and fewer chances for macrovoid formation $[24,25,67,68]$. In this work, 90s extra time was given to the membranes selected for evaporation prior to immersion in the coagulation bath (Table 2). For triacetin and diacetin, rejection was increased, as expected, compared to those membranes processed without evaporation. For glycerol-formal, where large experimental errors appeared, as well as for monoacetin, an opposite effect was surprisingly observed (Fig. 2).

Overall performances of present membranes that reached $>90 \% \mathrm{RB}$ rejections and their comparison with other lab-made as well as some commercial membranes that were all tested with a $\mathrm{RB} / \mathrm{H}_{2} \mathrm{O}$ feed, are given in Fig. 3.

The best membranes in this work were obtained using the diacetin/2MeTHF solvent system, depending on whether high rejection is preferred over high fluxes or vice versa. These membranes have a RB rejection higher than $90 \%$ with very good permeances.

Membranes discussed elsewhere often have better permeances with $\mathrm{RB}$ rejections around 99\%, but are obviously prepared using toxic and non-renewable solvents. Of all membranes prepared from glycerolbased solvents, none of the monoacetin-based and only one glycerolformal based membrane realized a rejection of $90 \%$. These are thus absent in Fig. 3. Also the other glycerol derivatised membranes in Fig. 3 did not manage to reach RB-rejections that were comparable to the literature systems. Obviously, also the membrane polymer is different in these papers.

\subsection{Kinetic aspects of phase inversion}

\subsubsection{General}

Both kinetic and thermodynamic aspects contribute to understanding the fundamental phase inversion effects on morphology and performance of membranes. In membrane fabrication, the kinetic aspect is related to the exchange rate of solvent (S) and non-solvent (NS). The driving force for this mass transfer depends on the difference in concentration of the components in both phases [24,25,69]. Diffusion of S and NS molecules depends on the size of these molecules and on the viscosity of the medium. After a while, liquid-liquid demixing of the polymer solution occurs. Due to differences in exchange rates and in polymer solution stability, two types of demixing processes can be distinguished. For instantaneous demixing, a membrane with a porous skin layer containing macrovoids is assumed to be formed. In the case of delayed demixing, a membrane with a relatively dense skin layer containing a sponge-like structure is formed [1]. The precise time span for delayed and instantaneous demixing is unclear in literature. Kinetic aspects can partially be understood via viscosity data. Viscosity measurements for the casting solutions with the 4 different solvent systems and with addition of 2-MeTHF are shown in Figs. 5 and 7 respectively.

\subsubsection{CA concentration}

As expected, viscosity of the casting solution increased with the increase of the CA-concentration in the casting solutions (Fig. 4), while it decreased with the addition of co-solvent (Fig. 6). Since high CAconcentrations in the casting solutions cause strong polymer chain entanglements in the solution [67]. Due to strong polymer chain entanglements in the casting solution, delayed demixing can be assumed. As a result, membranes with sponge-like structures are produced. This was indeed confirmed experimentally for the membranes cast from higher polymer concentrations (high viscosities) except for diacetin systems (Fig. 5).

The T9 membrane still had some kind of macrovoids but these disappeared as polymer concentration increased in the casting solution (Fig. 5). Following Fig. 5, this can be linked to the higher viscosity of the casting solution of T13 than T9 which delayed the diffusion rates.

Using diacetin, a low CA-concentration (10 $\mathrm{wt} \%)$ led to membranes with an uneven distribution of small macrovoids. With increasing CAconcentration in the casting solution, these macrovoids became more uniform and extended. At the higher CA-concentrations, a sponge-like structure was expected due to the increased viscosity of the casting solution, but also here, macrovoids were obtained, most probably due to the presence of other solvents as impurities in diacetin and the strong interaction $\left(R a_{S-N S}\right)$ between solvent and non-solvent.

\subsubsection{Co-solvent}

The low viscosity of 2-MeTHF could change the phase inversion process from delayed demixing toward faster demixing (Fig. 6) [67, 70-72], As seen in Fig. 7, this is only the case for glycerol formal. It is also noted that a more drastic change in viscosities takes place for polymer concentrations at which permeances (Fig. 2) change the least (except for triacetin). This suggests that other thermodynamic properties of the casting solution clearlyco-determine performance of the final membrane (see 3.3). At a low 2-MeTHF concentration in the casting solution, all membranes had high permeances with low RB-rejection. With the increase of 2-MeTHF concentration in the casting solution, permeances decreased and RB-rejection increased. with an increase of 2-MeTHF, less NS is needed for precipitation, irrespective of the solvent systems (except for triacetin where ethanol had to be used as NS - even though bio-based for sure, use of ethanol would lead to additional issues with respect to safety, cost and waste water treatment). For all solvent systems, the casting solutions containing $50 \mathrm{wt} \% 2$-MeTHF have the highest $R a_{S-N S}$ values. A high $R a_{S-N S}$ value represents a poor tendency of the two liquids to mix and the process of phase inversion will then tend more towards delayed demixing due to a lowered driving force for $\mathrm{S} / \mathrm{NS}$ exchange. As a result, the porosity of the membrane decreased, which favored the high RB-rejection.

Due to high 2-MeTHF concentration in the casting solution, the $R a_{S-N S}$ value increases, representing the poor tendency of these liquids to mix, thus possibly delaying demixing. All membranes prepared with triacetin with different concentration of 2-MeTHF have porous structures with very few but really large tear-shaped macrovoids in a very spongy matrix. The number of these macrovoids decreased with the increase of 2-MeTHF concentration in the casting solution while fewer macrovoids have huge spherical shape (Fig. 7). 
$13 \mathrm{wt} \% \mathrm{CA}$ in Triacetin $+2-\mathrm{MeTHF}$ in varying concentration

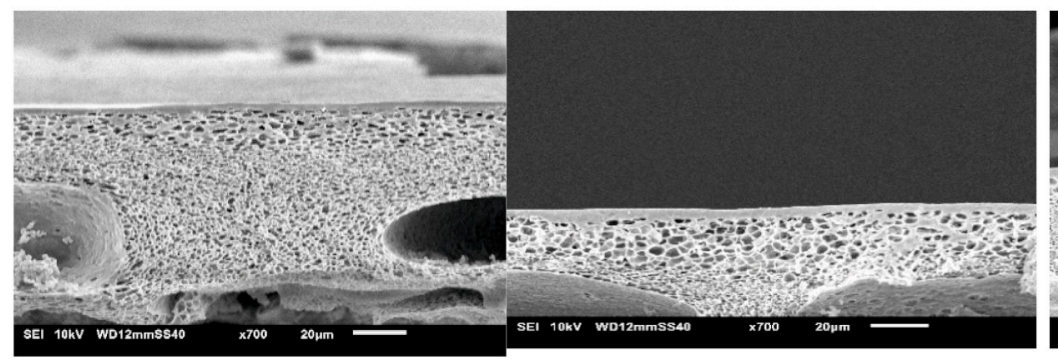

T13CS16
$\mathrm{T} 13 \mathrm{CS} 33$

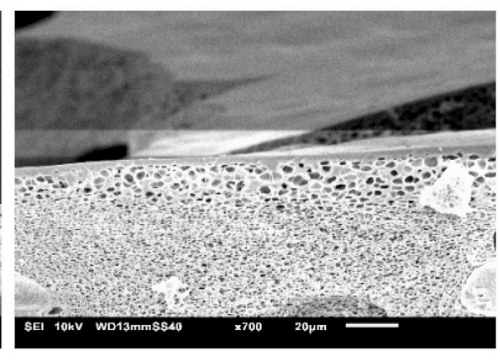

T13CS50

$16 \mathrm{wt} \% \mathrm{CA}$ in Diacetin+2-MeTHF in varying concentration

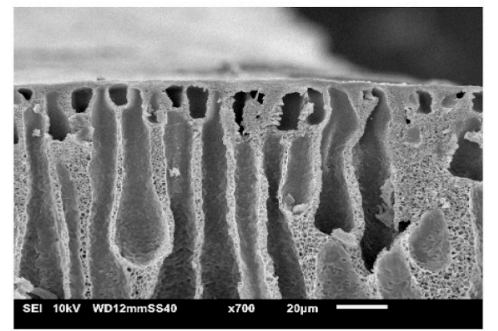

D13CS16

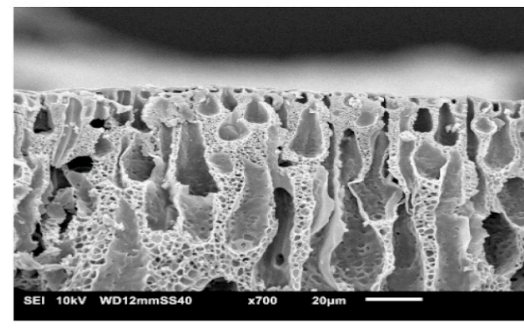

D13CS33

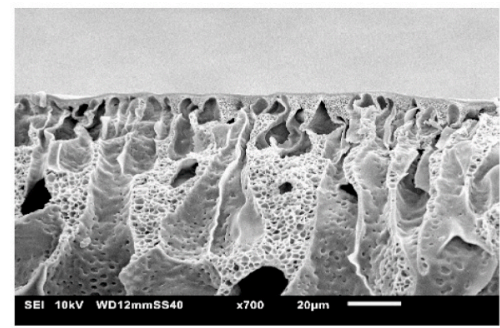

D13CS50

$14 \mathrm{wt} \% \mathrm{CA}$ in monoacetin+2-MeTHF in varying concentration

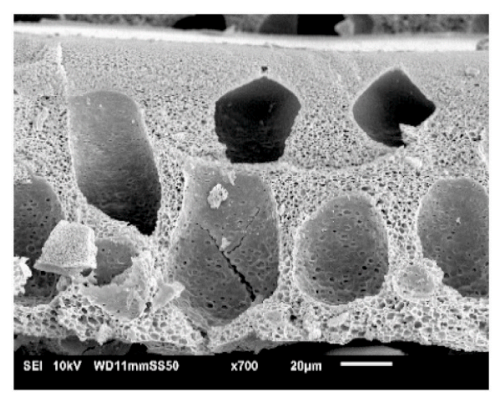

M13CS16

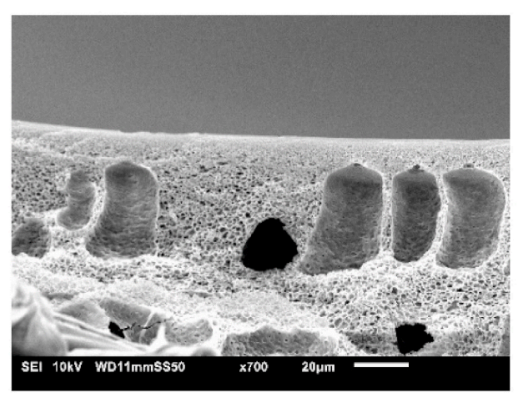

$\mathrm{M} 13 \mathrm{CS} 33$

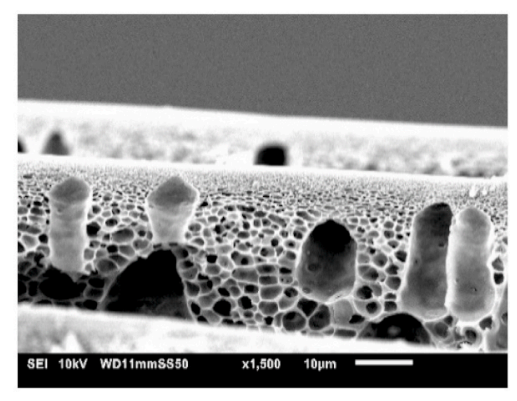

M13CS50

20wt $\% \mathrm{CA}$ in G.formal +2-MeTHF in varying concentration

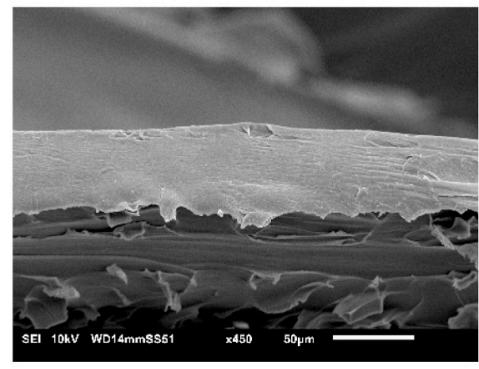

G13CS16

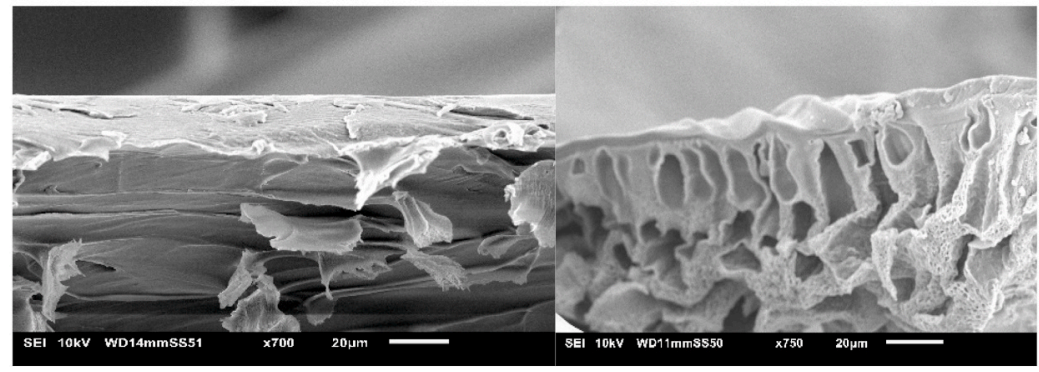

G13CS33

G13CS50

Fig. 7. SEM images of membranes prepared from different solvents with different co-solvent concentration in the casting solution.

For diacetin-based membranes, very pronounced finger-like macrovoids appeared, irrespective the 2-MeTHF concentration in the casting solution.

For CA/monoacetin with different 2-MeTHF concentration, membranes have porous structures with wide, oval-shaped macrovoids. With the increase of 2-MeTHF concentration in the casting solution, membranes became more porous with less macrovoids.

The biggest change in morphology was noticed using glycerol formal: with increasing co-solvent concentration, structure changed drastically and many macrovoids appeared (Fig. 7). In the case of 


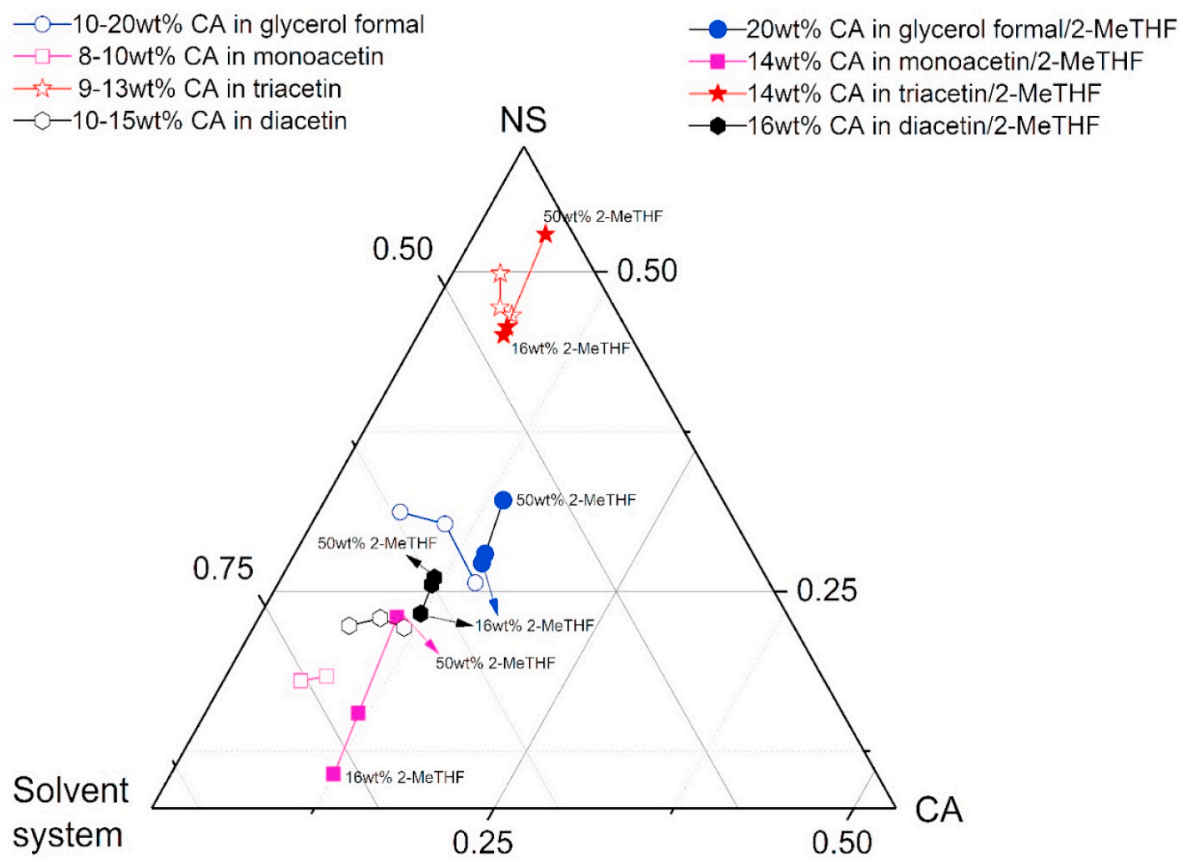

Fig. 8. Cloud points, plotted in the ternary phase diagram of CA using water as non-solvent (NS) and monoacetin, diacetin, triacetin, glycerol-formal as solvent system, with (full symbols) and without 2-MeTHF (open symbols). In the case of triacetin, ethanol was used as NS.

Table 4

Interaction distances $R a$ between $\mathrm{S}$ and NS verse NS and P interaction.

\begin{tabular}{|c|c|c|c|}
\hline Solvent system (S) & $\begin{array}{l}\text { Non-solvent } \\
\text { (NS) }\end{array}$ & $\begin{array}{l}R a(\mathrm{~S}-\mathrm{NS}) \\
\left(\mathrm{MPa}^{1 / 2}\right)\end{array}$ & $\begin{array}{l}R a \text { (NS-P) } \\
\left(\mathrm{MPa}^{1 / 2}\right)\end{array}$ \\
\hline Triacetin & Water & 35.2 & 30.0 \\
\hline Triacetin & Ethanol & 11.2 & 6.1 \\
\hline Triacetin/16\%2-MeTHF & Ethanol & 11.9 & 6.1 \\
\hline Triacetin/33\%2-MeTHF & Ethanol & 12.7 & 6.1 \\
\hline Triacetin/50\%2-MeTHF & Ethanol & 13.4 & 6.1 \\
\hline Monoacetin & Water & 23.4 & 30.0 \\
\hline $\begin{array}{l}\text { Monoacetin/16\%2- } \\
\text { MeTHF }\end{array}$ & Water & 25.8 & 30.0 \\
\hline $\begin{array}{l}\text { Monoacetin/33\%2- } \\
\text { MeTHF }\end{array}$ & Water & 28.3 & 30.0 \\
\hline $\begin{array}{l}\text { Monoacetin/50\%2- } \\
\text { MeTHF }\end{array}$ & Water & 31.1 & 30.0 \\
\hline Diacetin & Water & 29.1 & 30.0 \\
\hline Diacetin/16\%2-MeTHF & Water & 30.8 & 30.0 \\
\hline Diacetin/33\%2-MeTHF & Water & 32.5 & 30.0 \\
\hline Diacetin/50\%2-MeTHF & Water & 34.3 & 30.0 \\
\hline Glycerol formal & Water & 25.5 & 30.0 \\
\hline $\begin{array}{l}\text { Glycerol formal/16\%2- } \\
\text { MeTHF }\end{array}$ & Water & 27.6 & 30.0 \\
\hline $\begin{array}{l}\text { Glycerol formal/33\%2- } \\
\text { MeTHF }\end{array}$ & Water & 29.7 & 30.0 \\
\hline $\begin{array}{l}\text { Glycerol formal/50\%2- } \\
\text { MeTHF }\end{array}$ & Water & 32.2 & 30.0 \\
\hline
\end{tabular}

membranes cast from low 2-MeTHF concentrations (G13CS16 and G13CS33), no macrovoids were seen in membrane morphology, while macrovoids appeared in membrane morphology at high concentration (G13CS50).

All solvent systems have different viscosities and had a strong influence on the process of phase inversion. Due to the change in viscosity, the process of phase inversion followed either delayed demixing route or instantaneous demixing route, which created membranes with a spongelike structure or with macrovoids depending on the phase inversion route $[8,73,74]$.

\subsection{Thermodynamic aspects of phase inversion}

\subsubsection{General}

Cloudpoint measurements, as shown in Fig. 8, characterize the thermodynamics of polymer solutions. The phase diagram is made from cloudpoint measurements in which a homogenous CA-solution is titrated with a NS by visualizing the turbidity in the polymer solution [72,75-79]. The cloudpoints of all homogeneous CA-solutions were thus measured at $30{ }^{\circ} \mathrm{C}$ by adding water (or ethanol for triacetin). It is well-known that for high polymer concentrations in the casting solution, less non-solvent is needed to cause phase separation, since solutions with high polymer concentration are thermodynamically less stable. With increasing 2-MeTHF in the casting solution, less NS is needed for precipitation irrespective the solvent systems, except for triacetin (where ethanol had to be used as NS).

For all four solvent systems, the casting solutions containing $50 \mathrm{wt} \%$ 2-MeTHF have the highest $R a_{S-N S}$ values. A high $R a_{S-N S}$ value represents a poor tendency of the two liquids to mix and the process of phase inversion will then tend more towards delayed demixing due to a lowered driving force for S/NS exchange. In the case of ethanol as nonsolvent, the $R a_{S-N S}$ value are much lower than with water, representing a higher solvent non-solvent affinity (Table 4).

\subsubsection{Evaporation time before phase inversion}

Membrane morphology can notably be influenced by the introducing an evaporation step prior to immersion of the cast film into the nonsolvent. The viscosity of the casting solutions then increases due to the evaporation of the volatile co-solvent, thus delaying demixing and leading to spongy structures.

Triacetin-based membranes already had a sponge-like matrix (Fig. 7) and thus kept this. (Fig. 9).

In the case of diacetin-based membranes from casting solution with different 2-MeTHF concentration and processed with 90s evaporation, no different membrane morphology was found at all and, for sure, no spongy structure appeared. The membrane morphology of the diacetin/ 2-MeTHF system was thus less affected by evaporation, even though the effect of evaporation was clearly seen in the membrane performance.

Monoacetin-based membranes fully obeyed the expectations: 
$13 \mathrm{wt} \% \mathrm{CA}$ in triacetin $+2-\mathrm{MeTHF}$ in varying concentration

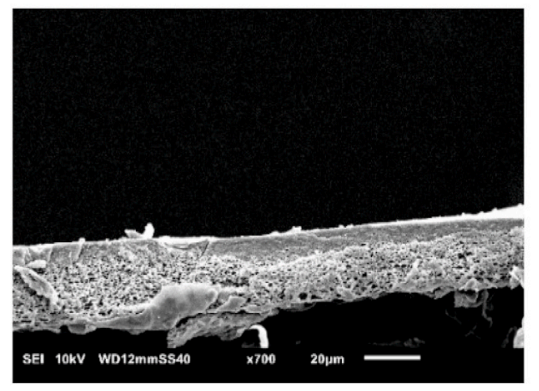

$\mathrm{T} 13 \mathrm{CS} 16 \mathrm{E}$

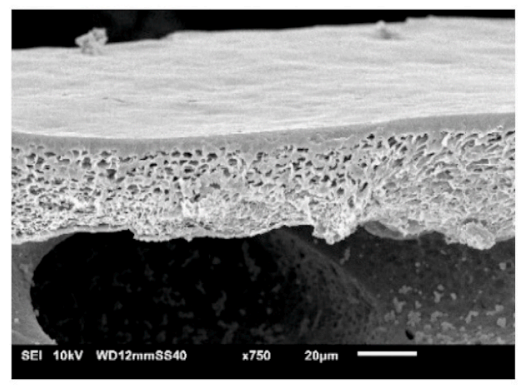

T13CS33E

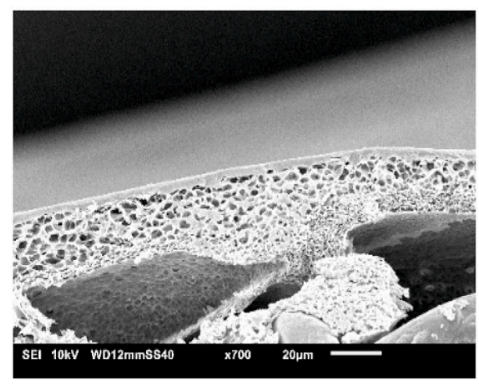

T13CS50E

$16 \mathrm{wt} \% \mathrm{CA}$ in diacetin $+2-\mathrm{MeTHF}$ in varying concentration

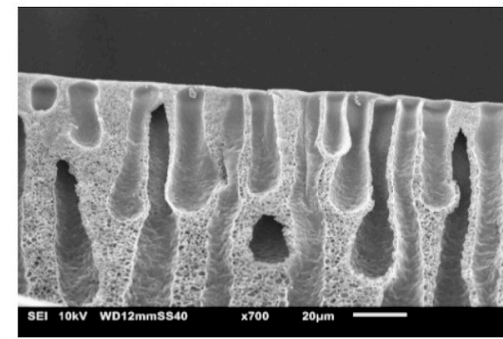

D13CS16E

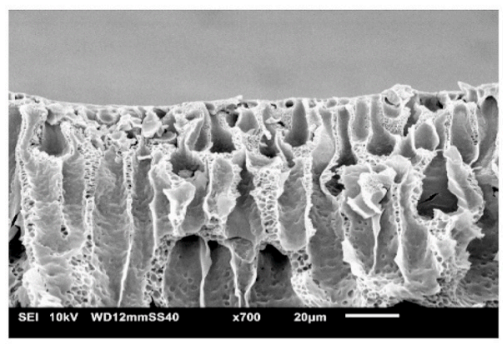

D13CS33E

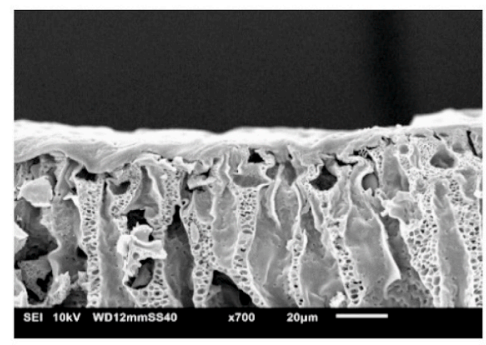

D13CS50E

$14 \mathrm{wt} \% \mathrm{CA}$ in monoacetin $+2-\mathrm{MeTHF}$ in varying concentration

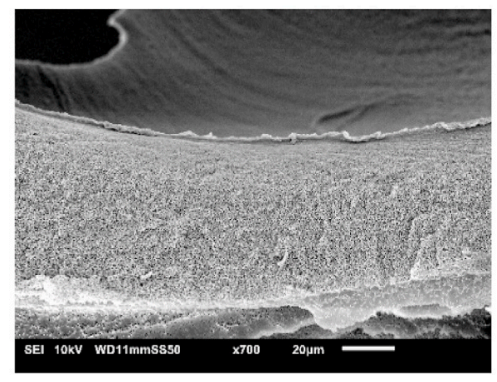

M13CS16E

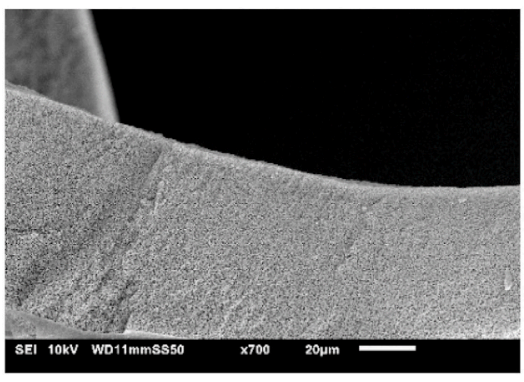

M13CS33E

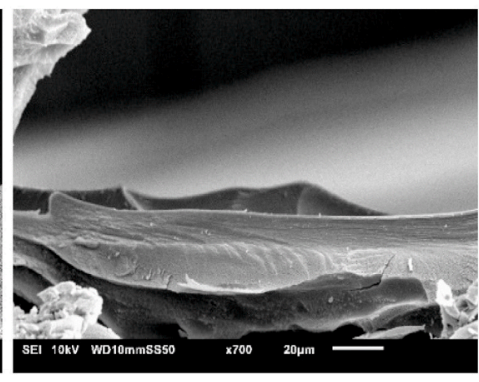

M13CS50E

$20 \mathrm{wt} \% \mathrm{CA}$ in glycerol formal $+2-\mathrm{MeTHF}$ in varying concentration

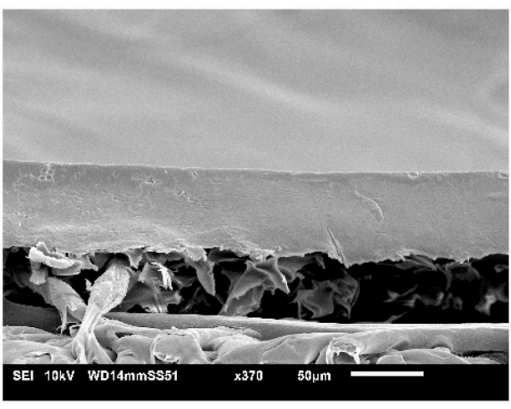

G13CS16E

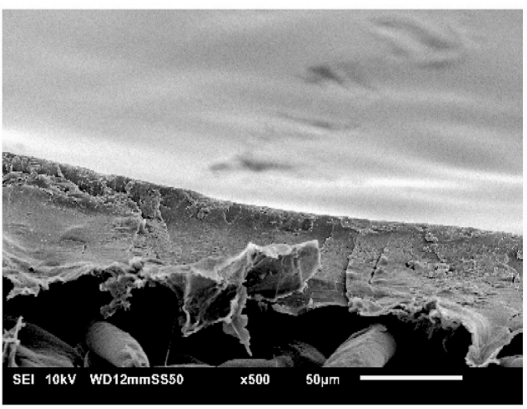

G13CS33E

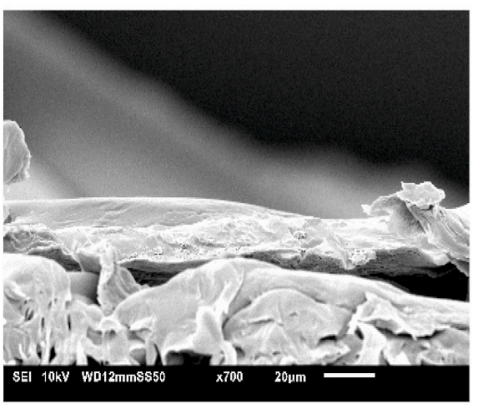

G13CS50E

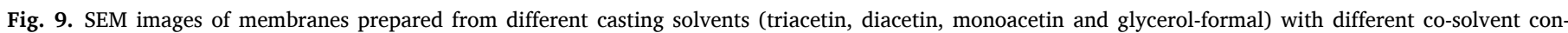
centration in the casting solution with 90s delay prior to non-solvent immersion. 
macrovoids completely disappeared when including evaporation. This sponge-like structure became denser with increasing co-solvent concentration in the casting solution.

Also with glycerol formal, macrovoids completely disappeared upon evaporation but no real sponge-like structure was formed (Fig. 9).

\section{Conclusions}

CA based membranes were successfully prepared using glycerol derivatives (triacetin, diacetin, monoacetin and glycerol-formal) via phase inversion to reach rejections in the NF range. With increasing CA and 2MeTHF concentrations in the casting solution, increased RB rejections could be realized. The best membranes were obtained from diacetin with addition of co-solvent resulting in a high permeance of $5.7-12.8 \mathrm{~L} / \mathrm{m}^{2} \mathrm{~h}$ bar with $\mathrm{RB}$ rejections over $90 \%$. In the case of triacetin, membranes prepared using 33-50\% 2Me-THF with evaporation, had RB rejection higher than $94.5 \%$ but permeance was less than $1.0 \mathrm{~L} / \mathrm{m}^{2} \mathrm{~h}$ bar. Membranes cast from monoacetin, had high fluxes but RB rejections below $25 \%$. Membranes cast from glycerol-formal with $50 \mathrm{wt} \%$ co-solvent, had a rejection around $90 \%$ with a permeance of $1.1 \mathrm{~L} / \mathrm{m}^{2} \mathrm{~h}$ bar.

Membrane morphologies and performances were linked to kinetics (viscosity) and thermodynamics. Increased viscosity of the casting solution favored delayed demixing. CA was more stable in the triacetin system and less stable in monoacetin system. The overall stability of CA in different solvent systems decreased on increasing 2-MeTHF concentration in the casting solution.

Among all glycerol derivative systems, the diacetin/co-solvent system is recommended for NF application due to the combined high permeance and high RB rejection of the resulting CA-membranes. The diacetin system was the one that did not follow the expectation when increasing polymer concentration in the casting solution (i.e. macrovoids stayed) and when adding more co-solvent (i.e. no change at all in morphology).

\section{CRediT authorship contribution statement}

Muhammad Azam Rasool: Conceptualization, Methodology, Formal analysis, Investigation, Writing - original draft, Writing - review \& editing. Ivo F.J. Vankelecom: Resources, Writing - review \& editing, Supervision.

\section{Declaration of competing interest}

The authors declare that they have no known competing financial interests or personal relationships that could have appeared to influence the work reported in this paper.

\section{Acknowledgements}

Dr. M. Azam Rasool deeply acknowledges Aurora Teodorescu (from Brasov Romania) currently working at amawaterways for fruitful discussion, helpful suggestions, and visiting Leuven Belgium during this work. KU Leuven is acknowledged for support through a C1-financing and FWO for an SBO-STW grant (Nanomexico).

\section{Appendix A. Supplementary data}

Supplementary data to this article can be found online at https://doi. org/10.1016/j.memsci.2020.118674.

\section{References}

[1] M. Mulder, Basic Principles of Membrane Technology, Springer Netherlands, Dordrecht, 1996, https://doi.org/10.1007/978-94-009-1766-8.

[2] I. Soroko, Y. Bhole, A.G. Livingston, Environmentally friendly route for the preparation of solvent resistant polyimide nanofiltration membranes, Green Chem. 13 (2011) 162, https://doi.org/10.1039/c0gc00155d.
[3] P. Marchetti, M.F.J. Solomon, G. Szekely, A.G. Livingston, Molecular Separation with Organic Solvent Nanofiltration: A Critical Review, 2014, https://doi.org/ 10.1021/cr500006j.

[4] I.B. Valtcheva, S.C. Kumbharkar, J.F. Kim, Y. Bhole, A.G. Livingston, Beyond polyimide: crosslinked polybenzimidazole membranes for organic solvent nanofiltration (OSN) in harsh environments, J. Membr. Sci. 457 (2014) 62-72, https://doi.org/10.1016/J.MEMSCI.2013.12.069.

[5] A. Cano-Odena, M. Spilliers, T. Dedroog, K. De Grave, J. Ramon, I.F.J. Vankelecom, Optimization of cellulose acetate nanofiltration membranes for micropollutant removal via genetic algorithms and high throughput experimentation, J. Membr. Sci. 366 (2011) 25-32, https://doi.org/10.1016/j.memsci.2010.09.026.

[6] K. Vanherck, A. Cano-Odena, G. Koeckelberghs, T. Dedroog, I. Vankelecom, A simplified diamine crosslinking method for PI nanofiltration membranes, J. Membr. Sci. 353 (2010) 135-143, https://doi.org/10.1016/j. memsci.2010.02.046.

[7] X. Li, P. Vandezande, I.F.J. Vankelecom, Polypyrrole modified solvent resistant nanofiltration membranes, J. Membr. Sci. 320 (2008) 143-150, https://doi.org/ 10.1016/j.memsci.2008.03.061.

[8] E. Saljoughi, T. Mohammadi, Cellulose acetate (CA)/polyvinylpyrrolidone (PVP) blend asymmetric membranes: preparation, morphology and performance, Desalination 249 (2009) 850-854, https://doi.org/10.1016/J. DESAL. 2008.12.066.

[9] Long D. Nghiem, Andrea I. Schäfer, Menachem Elimelech, Pharmaceutical Retention Mechanisms by Nanofiltration Membranes, 2005, https://doi.org/ 10.1021/ES0507665.

[10] P. Vandezande, L.E.M. Gevers, I.F.J. Vankelecom, Solvent resistant nanofiltration: separating on a molecular level, Chem. Soc. Rev. 37 (2008) 365-405, https://doi. org/10.1039/B610848M.

[11] P. Marchetti, M.F. Jimenez Solomon, G. Szekely, A.G. Livingston, Molecular separation with organic solvent nanofiltration: a critical review, Chem. Rev. 114 (2014) 10735-10806, https://doi.org/10.1021/cr500006j.

[12] Y.H. See Toh, F.W. Lim, A.G. Livingston, Polymeric membranes for nanofiltration in polar aprotic solvents, J. Membr. Sci. 301 (2007) 3-10, https://doi.org/ 10.1016/j.memsci.2007.06.034.

[13] J. Su, Q. Yang, J.F. Teo, T.S. Chung, Cellulose acetate nanofiltration hollow fiber membranes for forward osmosis processes, J. Membr. Sci. 355 (2010) 36-44, https://doi.org/10.1016/j.memsci.2010.03.003.

[14] M. Paul, S.D. Jons, Chemistry and fabrication of polymeric nanofiltration membranes: a review, Polymer 103 (2016) 417-456, https://doi.org/10.1016/J. POLYMER.2016.07.085.

[15] C.J. Clarke, W.-C. Tu, O. Levers, A. Bröhl, J.P. Hallett, Green and sustainable solvents in chemical processes, Chem. Rev. 118 (2018) 747-800, https://doi.org/ 10.1021/acs.chemrev.7b00571.

[16] A. Amelio, G. Genduso, S. Vreysen, P. Luis, B. Van der Bruggen, Guidelines based on life cycle assessment for solvent selection during the process design and evaluation of treatment alternatives, Green Chem. 16 (2014) 3045-3063, https:// doi.org/10.1039/C3GC42513D.

[17] R.K. Henderson, C. Jiménez-González, D.J.C. Constable, S.R. Alston, G.G.a. Inglis, G. Fisher, J. Sherwood, S.P. Binks, A.D. Curzons, Expanding GSK's solvent selection guide - embedding sustainability into solvent selection starting at medicinal chemistry, Green Chem. 13 (2011) 854, https://doi.org/10.1039/c0gc00918k.

[18] A. Figoli, T. Marino, S. Simone, E. Di Nicolò, X.-M. Li, T. He, S. Tornaghi, E. Drioli, Towards non-toxic solvents for membrane preparation: a review, Green Chem. 16 (2014) 4034, https://doi.org/10.1039/C4GC00613E.

[19] R. Kumar Sanju, S. Ahalawat, K.P. Singh, Study of mixed membrane potential with surface modified cellulose acetate nanofilter, Anal. Chem. Lett. 4 (2014) 158-171, https://doi.org/10.1080/22297928.2014.969615.

[20] P.T. Anastas, Green chemistry as applied to solvents, Clean Solvents 1991 (2002) $1-9$.

[21] C. Capello, U. Fischer, K. Hungerbühler, What is a green solvent? A comprehensive framework for the environmental assessment of solvents, Green Chem. 9 (2007) 927-934, https://doi.org/10.1039/b617536h.

[22] W.J. Schell, C.G. Wensley, M.S.K. Chen, K.G. Venugopal, B.D. Miller, J.A. Stuart, Recent advances in cellulosic membranes for gas separation and pervaporation, Gas Separ. Purif. 3 (1989) 162-169, https://doi.org/10.1016/0950-4214(89) 80001-5.

[23] A. Cano-Odena, M. Spilliers, T. Dedroog, K. De Grave, J. Ramon, I.F.J. Vankelecom, Optimization of cellulose acetate nanofiltration membranes for micropollutant removal via genetic algorithms and high throughput experimentation, J. Membr. Sci. 366 (2011) 25-32, https://doi.org/10.1016/j.memsci.2010.09.026.

[24] A.K. Holda, I.F.J. Vankelecom, Understanding and guiding the phase inversion process for synthesis of solvent resistant nanofiltration membranes, J. Appl. Polym. Sci. 132 (2015) 1-17, https://doi.org/10.1002/app.42130.

[25] A.K. Hołda, B. Aernouts, W. Saeys, I.F.J. Vankelecom, Study of polymer concentration and evaporation time as phase inversion parameters for polysulfonebased SRNF membranes, J. Membr. Sci. 442 (2013) 196-205, https://doi.org/ 10.1016/j.memsci.2013.04.017.

[26] A.K. Hołda, I.F.J. Vankelecom, Integrally skinned PSf-based SRNF-membranes prepared via phase inversion-Part B: influence of low molecular weight additives, J. Membr. Sci. 450 (2014) 499-511, https://doi.org/10.1016/j. memsci.2013.08.051.

[27] B. Van Der Bruggen, J.C. Jansen, A. Figoli, J. Geens, K. Boussu, E. Drioli, Characteristics and performance of a "universal" membrane suitable for gas separation, Pervaporation, and Nanofiltration Applications (2006), https://doi org/10.1021/jp0608933. 
[28] R. Haddad, E. Ferjani, M.S. Roudesli, A. Deratani, Properties of cellulose acetate nanofiltration membranes. Application to brackish water desalination, Desalination 167 (2004) 403-409, https://doi.org/10.1016/j.desal.2004.06.154.

[29] V. Siracusa, P. Rocculi, S. Romani, M.D. Rosa, Biodegradable polymers for food packaging: a review, Trends Food Sci. Technol. 19 (2008) 634-643, https://doi. org/10.1016/j.tifs.2008.07.003.

[30] T. Ishigaki, W. Sugano, A. Nakanishi, M. Tateda, M. Ike, M. Fujita, The degradability of biodegradable plastics in aerobic and anaerobic waste landfill model reactors, Chemosphere 54 (2004) 225-233, https://doi.org/10.1016/ S0045-6535(03)00750-1.

[31] K. Vanherck, G. Koeckelberghs, I.F.J. Vankelecom, Crosslinking polyimides for membrane applications: a review, Prog. Polym. Sci. 38 (2013) 874-896, https:// doi.org/10.1016/j.progpolymsci.2012.11.001.

[32] Y.H. See Toh, X.X. Loh, K. Li, A. Bismarck, A.G. Livingston, In search of a standard method for the characterisation of organic solvent nanofiltration membranes, J. Membr. Sci. 291 (2007) 120-125, https://doi.org/10.1016/j. memsci.2006.12.053.

[33] I.B. Valtcheva, S.C. Kumbharkar, J.F. Kim, Y. Bhole, A.G. Livingston, Beyond polyimide: crosslinked polybenzimidazole membranes for organic solvent nanofiltration (OSN) in harsh environments, J. Membr. Sci. 457 (2014) 62-72, https://doi.org/10.1016/j.memsci.2013.12.069.

[34] P. Vandezande, X. Li, L.E.M. Gevers, I.F.J. Vankelecom, High throughput study of phase inversion parameters for polyimide-based SRNF membranes, J. Membr. Sci. 330 (2009) 307-318, https://doi.org/10.1016/j.memsci.2008.12.068.

[35] P. Marchetti, M.F.J. Solomon, G. Szekely, A.G. Livingston, Molecular separation with organic solvent nano fi ltration : a critical review, Chem. Rev. 114 (2014) 10735-10806, https://doi.org/10.1021/cr500006j.

[36] S. Bey, A. Criscuoli, S. Simone, A. Figoli, M. Benamor, E. Drioli, Hydrophilic PEEKWC hollow fibre membrane contactors for chromium (Vi) removal, Desalination 283 (2011) 16-24, https://doi.org/10.1016/j.desal.2011.04.038.

[37] M.A. Rasool, I.F.J. Vankelecom, Use of $\gamma$-valerolactone and glycerol derivatives as bio-based renewable solvents for membrane preparation, Green Chem. 21 (2019) 1054-1064, https://doi.org/10.1039/c8gc03652g.

[38] M.A. Rasool, C. Van Goethem, I.F.J. Vankelecom, Green preparation process using methyl lactate for cellulose-acetate-based nanofiltration membranes, Separ. Purif. Technol. (2019) 115903, https://doi.org/10.1016/j.seppur.2019.115903.

[39] F. Galiano, Abdulsattar, H. Ghanim, Khalid, T. Rashid, T. Marino, S. Simone, Qusay, F. Alsalhy, A. Figoli, Preparation and Characterization of Green Polylactic Acid (PLA) Membranes for Organic/organic Separation by Pervaporation, vol. 21, 2019, pp. 109-120, https://doi.org/10.1007/s10098-018-1621-4.

[40] Y. Medina-Gonzalez, P. Aimar, J.-F. Lahitte, J.-C. Remigy, Towards green membranes: preparation of cellulose acetate ultrafiltration membranes using methyl lactate as a biosolvent, International Journal of Sustainable Engineering 4 (2011) 75-83, https://doi.org/10.1080/19397038.2010.497230.

[41] M. mi Tao, F. Liu, B. rong Ma, L. xin Xue, Effect of solvent power on PVDF membrane polymorphism during phase inversion, Desalination 316 (2013) 137-145, https://doi.org/10.1016/j.desal.2013.02.005.

[42] H. Mariën, L. Bellings, S. Hermans, I.F.J. Vankelecom, Sustainable process for the preparation of high-performance thin-film composite membranes using ionic liquids as the reaction medium, ChemSusChem 9 (2016) 1101-1111, https://doi. org $/ 10.1002 /$ cssc. 201600123.

[43] D.Y. Xing, N. Peng, T.-S. Chung, Formation of cellulose acetate membranes via phase inversion using ionic liquid, [BMIM] SCN, as the solvent, Ind. Eng. Chem. Res. 49 (2010) 8761-8769.

[44] M. Sairam, E. Sereewatthanawut, K. Li, A. Bismarck, A.G. Livingston, Method for the preparation of cellulose acetate flat sheet composite membranes for forward osmosis-desalination using MgSO4 draw solution, Desalination 273 (2011) 299-307, https://doi.org/10.1016/J.DESAL.2011.01.050.

[45] S. Hermans, E. Dom, H. Mariën, G. Koeckelberghs, I.F.J. Vankelecom, Efficient synthesis of interfacially polymerized membranes for solvent resistant nanofiltration, J. Membr. Sci. 476 (2015) 356-363, https://doi.org/10.1016/j. memsci.2014.11.046.

[46] K. Hendrix, K. Vanherck, I.F.J. Vankelecom, Optimization of solvent resistant nanofiltration membranes prepared by the in-situ diamine crosslinking method, J. Membr. Sci. 421-422 (2012) 15-24, https://doi.org/10.1016/j. memsci.2012.06.022.

[47] K. Hendrix, M. Vaneynde, G. Koeckelberghs, I.F.J. Vankelecom, Synthesis of modified poly(ether ether ketone) polymer for the preparation of ultrafiltration and nanofiltration membranes via phase inversion, J. Membr. Sci. 447 (2013) 96-106, https://doi.org/10.1016/j.memsci.2013.07.006.

[48] D. Kim, N.L. Le, S.P. Nunes, The effects of a co-solvent on fabrication of cellulose acetate membranes from solutions in 1-ethyl-3-methylimidazolium acetate, J. Membr. Sci. 520 (2016) 540-549, https://doi.org/10.1016/J. MEMSCI.2016.08.015.

[49] H. Mariën, I.F.J. Vankelecom, Transformation of cross-linked polyimide UF membranes into highly permeable SRNF membranes via solvent annealing, J. Membr. Sci. 541 (2017) 205-213, https://doi.org/10.1016/j. memsci.2017.06.080.

[50] J. Liu, X.-L. Lu, C.-R. Wu, Effect of annealing conditions on crystallization behavior and mechanical properties of NIPS poly(vinylidene fluoride) hollow fiber membranes, J. Appl. Polym. Sci. 129 (2013) 1417-1425, https://doi.org/10.1002/ app.38845.

[51] Y.H. See-Toh, F.C. Ferreira, A.G. Livingston, The influence of membrane formation parameters on the functional performance of organic solvent nanofiltration membranes, J. Membr. Sci. 299 (2007) 236-250, https://doi.org/10.1016/J. MEMSCI.2007.04.047.
[52] S. Oecd, Glycerol cas N: 56-81-5, 2002, pp. 56-81. https://hpvchemicals.oecd. org/ui/handler.axd?id=4b0a2d87-3183-40d4-84f5-0e118c647b19.

[53] J.A. Arnot, F.A.P.C. Gobas, A review of bioconcentration factor (BCF) and bioaccumulation factor (BAF) assessments for organic chemicals in aquatic organisms, Environ. Rev. 14 (2006) 257-297, https://doi.org/10.1139/a06-005.

[54] A. Wolfson, C. Dlugy, Y. Shotland, Glycerol as a green solvent for high product yields and selectivities, Environ. Chem. Lett. 5 (2007) 67-71, https://doi.org/ 10.1007/s10311-006-0080-z.

[55] K. Pathak, K.M. Reddy, N.N. Bakhshi, A.K. Dalai, Catalytic conversion of glycerol to value added liquid products, Appl. Catal. Gen. 372 (2010) 224-238, https://doi. org/10.1016/j.apcata.2009.10.036

[56] A.E. Díaz-Álvarez, J. Francos, B. Lastra-Barreira, P. Crochet, V. Cadierno, Glycerol and derived solvents: new sustainable reaction media for organic synthesis, Chem. Commun. 47 (2011) 6208-6227, https://doi.org/10.1039/C1CC10620A.

[57] G. Anastopoulos, Y. Zannikou, S. Stournas, S. Kalligeros, Transesterification of vegetable oils with ethanol and characterization of the key fuel properties of ethyl esters, Energies 2 (2009) 362-376, https://doi.org/10.3390/en20200362.

[58] D.F. Aycock, Solvent applications of 2-methyltetrahydrofuran in organometallic and biphasic reactions, Org. Process Res. Dev. 11 (2007) 156-159, https://doi.org/ 10.1021/op060155c.

[59] M.A. Rasool, P.P. Pescarmona, I.F.J. Vankelecom, Applicability of organic carbonates as green solvents for membrane preparation, ACS Sustain. Chem. Eng. (2019), https://doi.org/10.1021/acssuschemeng.9b01507.

[60] C.M. Hansen, Hansen Solubility Parameters, CRC press Taylor \&Francis Group, 2013, https://doi.org/10.1017/CBO9781107415324.004.

[61] A.F.M. Barton, CRC Handbook of Solubility Parameters and Other Cohesion Parameters, CRC Press, 1991.

[62] Y.H. See-Toh, F.C. Ferreira, A.G. Livingston, The influence of membrane formation parameters on the functional performance of organic solvent nanofiltration membranes, J. Membr. Sci. 299 (2007) 236-250.

[63] V. Altun, J.C. Remigy, I.F.J. Vankelecom, UV-cured polysulfone-based membranes: effect of co-solvent addition and evaporation process on membrane morphology and SRNF performance, J. Membr. Sci. 524 (2017) 729-737, https://doi.org/ 10.1016/j.memsci.2016.11.060.

[64] https://www.sigmaaldrich.com/content/dam/sigma-aldrich/docs/Sigma/Brochu re/greener_solvent_alternatives.pdf?utm_source=redirect\&utm_medium=promot ional\&utm_campaign=insite_greener_solvent_alternatives. (Accessed 25 May 2020).

[65] P. Vandezande, L.E.M. Gevers, I.F.J. Vankelecom, Solvent resistant nanofiltration: separating on a molecular level, Chem. Soc. Rev. 37 (2008) 365-405, https://doi. org/10.1039/B610848M.

[66] I.M.W.C.A. Smolders, A.J. Reuvers, R.M. Boom, Microstructures in phaseinversionmembranes .1. Formation of macrovoids, J. Membr. Sci. 73 (1992) 259-275.

[67] A.F. Ismail, L.P. Yean, Review on the development of defect-free and ultrathinskinned asymmetric membranes for gas separation through manipulation of phase inversion and rheological factors, J. Appl. Polym. Sci. 88 (2003) 442-451, https:// doi.org/10.1002/app.11744.

[68] F.G. Paulsen, S.S. Shojaie, W.B. Krantz, Effect of evaporation step on macrovoid formation in wet-cast polymeric membranes, J. Membr. Sci. 91 (1994) 265-282, https://doi.org/10.1016/0376-7388(94)80088-X.

[69] K. Kimmerle, H. Strathmann, Analysis of the structure-determining process of phase inversion membranes, Desalination 79 (1990) 283-302, https://doi.org/ 10.1016/0011-9164(90)85012-Y.

[70] T. Chung, E.R. Kafchinski, The effects of spinning conditions on asymmetric 6FDA/ 6FDAM polyimide hollow fibers for air separation, J. Appl. Polym. Sci. 65 (1998) 1555-1569, https://doi.org/10.1002/(SICI)1097-4628(19970822)65:8<1555: AID-APP13>3.0.CO;2-V.

[71] T.S. Chung, S.K. Teoh, X. Hu, Formation of ultrathin high-performance polyethersulfone hollow-fiber membranes, J. Membr. Sci. 133 (1997) 161-175, https://doi.org/10.1016/S0376-7388(97)00101-4.

[72] R. Koningsveld, A.J. Staverman, Liquid-liquid phase separation in multicomponent polymer solutions, Kolloid-Z. Z. Polym. 220 (1967) 31-40, https://doi.org/ 10.1007/BF02086054.

[73] K. Hendrix, M. Vaneynde, G. Koeckelberghs, I.F.J. Vankelecom, Synthesis of Modi Fi Ed Poly (Ether Ether Ketone) Polymer for the Preparation of Ultra Fi Ltration and Nano Fi Ltration Membranes via Phase Inversion, vol. 447, 2013, pp. 96-106, https://doi.org/10.1016/j.memsci.2013.07.006.

[74] F.G. Paulsen, S.S. Shojaie, W.B. Krantz, Effect of evaporation step on macrovoid formation in wet-cast polymeric membranes, J. Membr. Sci. 91 (1994) 265-282, https://doi.org/10.1016/0376-7388(94)80088-X.

[75] R.M. Boom, T. van den Boomgaard, J.W.A. van den Berg, C.A. Smolders, Linearized cloudpoint curve correlation for ternary systems consisting of one polymer, one solvent and one non-solvent, Polymer 34 (1993) 2348-2356, https://doi.org/ 10.1016/0032-3861(93)90819-V.

[76] W.W.Y. Lau, M.D. Guiver, T. Matsuura, Phase separation in polysulfone/solvent/ water and polyethersulfone/solvent/water systems, J. Membr. Sci. 59 (1991) 219-227, https://doi.org/10.1016/S0376-7388(00)81185-0.

[77] C.A. Smolders, A.J. Reuvers, R.M. Boom, I.M. Wienk, Microstructures in phaseinversion membranes. Part 1. Formation of macrovoids, J. Membr. Sci. 73 (1992) 259-275, https://doi.org/10.1016/0376-7388(92)80134-6.

[78] R.M. Boom, I.M. Wienk, T. van den Boomgaard, C.A. Smolders, Microstructures in phase inversion membranes. Part 2. The role of a polymeric additive, J. Membr. Sci. 73 (1992) 277-292, https://doi.org/10.1016/0376-7388(92)80135-7.

[79] M.A.M. Beerlage, M.L. Heijnen, M.H.V. Mulder, C.A. Smolders, H. Strathmann, Non-aqueous retention measurements: ultrafiltration behaviour of polystyrene 
solutions and colloidal silver particles, J. Membr. Sci. (1996) 259-273, https://doi. org/10.1016/0376-7388(95)00125-5. Elsevier Science B.V. 